\title{
Perdas de nitrogênio do solo e resposta do pessegueiro à adição de composto orgânico
}

\author{
Loss of soil nitrogen and peach yield with the addition of organic compost
}

\author{
Paula Beatriz Sete ${ }^{\mathrm{I}}$ George Wellington Bastos de Melo ${ }^{\mathrm{II}}$ Bruno Salvador Oliveira ${ }^{\mathrm{I}}$ \\ Rafael Fernando Freitas ${ }^{\text {III }}$ Renan Dal Magro ${ }^{\text {III }}$ Vitor Gabriel Ambrosini ${ }^{I}$ Talita Trapp ${ }^{\text {IV }}$ \\ Jucinei José Comin ${ }^{I}$ Luciano Colpo Gatiboniv Gustavo Brunetto ${ }^{\text {VI }}$
}

\section{RESUMO}

A aplicação de composto orgânico no solo pode incrementar a produção de pêssego, porém parte do $N$ pode ser perdido por lixiviação e volatilização. O trabalho objetivou avaliar o estado nutricional das plantas, a produção de pêssego, a lixiviação de formas de $\mathrm{N}$ no solo e a volatilização de $\mathrm{N}-\mathrm{NH}_{3}$ em um pomar de pessegueiro com a adição de composto orgânico produzido a partir de resíduos de agroindústrias de suco, resíduos de abatedouro de aves e serragem. $O$ pomar foi implantado em 2009 e, em julho de 2010, 2011 e 2012, foram aplicados 0, 3, 6, 12 e 24L de composto por $m^{2}$ e avaliaram-se os teores totais de nutrientes nas folhas e a produção. Em 2012, usando lisimetros instalados a 20 e a $40 \mathrm{~cm}$ de profundidade, avaliaram-se as formas de $N$ lixiviadas na solução percolada nos tratamentos 0 e $24 L$ de composto. Usando câmeras coletoras, foi avaliada a volatilização de $\mathrm{N}-\mathrm{NH}_{3}$ em todos os tratamentos até $478 \mathrm{~h}$ depois da deposição do composto no solo. A aplicação de composto na superficie do solo incrementou o teor de K e N nas folhas completas, aumentando a produção de frutos. A aplicação de composto no florescimento aumentou a concentração de nitrato na solução do solo, somente na profundidade de $20 \mathrm{~cm}$. A emissão de amônia aumentou com o incremento da dose de composto aplicado, especialmente e nos periodos de maior temperatura.

Palavras-chave: resíduo orgânico, $N$ mineral, Prunus persica.

\section{ABSTRACT}

The application of organic compost to the soil can increase the production of peach, although part of the $N$ may be lost by leaching and volatilization. The aim of this study was to evaluate the nutritional status, yield of peaches, leaching of $N$ forms and volatilization of $\mathrm{NH}_{3}-\mathrm{N}$ in a peach orchard with the addition of compost produced from agroindustrial juice waste, poultry slaughterhouse residues and sawdust. The orchard was established in 2009, and in july 2010, 2011 and 2012 the quantities of $0,3,6,12$ and $24 L$ of organic compost per $m^{2}$ were applied on a peach orchard and the total nutrient content in leaves and production was evaluated. In 2012, using lysimeters installed at 20 and $40 \mathrm{~cm}$ deep in the soil, it was measured the forms of $N$ in the solution in the treatments of 0 and $24 L$ of compost. The volatilization of $\mathrm{NH}_{3}-\mathrm{N}$ was assessed in all the treatments up to $478 \mathrm{~h}$ after compost application on the soil. The application of compost on the soil surface increased the content of $K$ and $N$ in whole leaves, increasing fruit production. The compost application at flowering increased the concentration of nitrate in the soil solution at a depth of only $20 \mathrm{~cm}$. The ammonia emission increased especially with the augmenting dose of compost applied, and in periods of higher temperature.

Key words: organic waste, mineral $N$, Prunus persica.

\section{INTRODUÇÃO}

A necessidade da adubação nitrogenada de manutenção do pessegueiro (Prunus persica L. Batsch) no Rio Grande do Sul (RS) e em Santa

\footnotetext{
IPrograma de Pós-graduação em Agroecossistemas (PGA), Departamento de Engenharia Rural, Universidade Federal de Santa Catarina (UFSC), Florianópolis, SC, Brasil.

"Empresa Brasileira de Pesquisa Agropecuária (Embrapa) Uva e Vinho, Bento Gonçalves, RS, Brasil.

IIICurso de Engenharia de Bioprocessos e Biotecnologia, Universidade do Estado do Rio Grande do Sul (UERGS), Bento Gonçalves, RS, Brasil.

${ }^{\text {IV }}$ Curso de Agronomia, UFSC, Florianópolis, SC, Brasil.

vPrograma de Pós-graduação em Ciência do Solo (PPGCS), Departamento de Solos, Universidade do Estado de Santa Catarina (UDESC), Lages, SC, Brasil.

vIPrograma de Pós-graduação em Ciência do Solo (PPGCS), Departamento de Solos, Universidade Federal de Santa Maria (UFSM), 97105-900, Santa Maria, RS, Brasil. E-mail: brunetto.gustavo@gmail.com.Autor para correspondência. Recebido 17.09.13 Aprovado 18.09.14 Devolvido pelo autor 10.12.14 CR-2013-1232.R2
} 
Catarina (SC) é estabelecida com base no teor total de $\mathrm{N}$ nas folhas completas, no crescimento dos ramos do ano e na produtividade esperada (CQFSRS/SC, 2004; BRUNETTO et al., 2007). Quando definida a necessidade, além da ureia, em função da disponibilidade, podem ser usadas outras fontes, como o composto orgânico derivado de resíduos de agroindústrias de suco, de abatedouro de aves e serragem. Em geral, na adubação de manutenção, o composto é aplicado na superfície do solo sem incorporação, para evitar danos mecânicos às raízes.

Em solos de pomares, especialmente naqueles degradados química, física e biologicamente, o composto pode incrementar o teor de carbono orgânico, o que favorece a agregação do solo, melhorando a estrutura, a porosidade, a capacidade de armazenamento de água e aumentando a disponibilidade de nutrientes no solo, como as formas de $\mathrm{N}$, por causa da mineralização do composto (KRAMER et al., 2002). Com isso, esperase uma maior emissão de raízes brancas e mais finas (SCANDELARI et al., 2010), que são responsáveis pela absorção de água e nutrientes do solo. Então, pode ocorrer aumento do teor de nutrientes no interior das plantas, diagnosticado pela análise foliar, e o aumento dos valores de componentes de produção, como a massa e o diâmetro dos frutos, possibilitando maior produção de frutos (BRAVO et al., 2012). No entanto, as melhorias nas características e a disponibilidade de formas de $\mathrm{N}$ em solos são dependentes, dentre outros fatores, da dose do composto aplicado. Isso porque, quanto maior a dose aplicada, menor será o contato com o solo, o que pode retardar a atividade da biomassa microbiana e, por consequência, a sua mineralização (KRAMER et al., 2002).

Uma parte do $\mathrm{N}$ mineralizado e que não é absorvido pelos pessegueiros pode ser lixiviado na forma de $\mathrm{N}-\mathrm{NO}_{3}{ }^{-}$por causa da sua baixa adsorção ao solo (ERHART et al., 2007), permanecendo em maior concentração na solução. Outra parte do $\mathrm{N}$ derivado da mineralização pode ser volatilizada na forma de

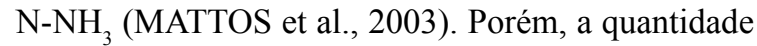
de formas de $\mathrm{N}$ lixiviadas e de $\mathrm{N}-\mathrm{NH}_{3}$ volatilizada é dependente da composição do composto aplicado, da sua dose e de condições climáticas, como precipitações e temperatura do ar (ERHART et al., 2007). Alguns trabalhos relatam que parte do $\mathrm{N}$ do composto orgânico aplicado na superfície do solo em pomares pode ser transferida para a atmosfera e lixiviado no perfil; mas as quantidades transferidas são muito dependentes da dose de composto adicionada e do tipo de solo (ROSEN \& ALLAN, 2007; BRAVO et al., 2012; LORENSINI et al., 2012). O trabalho objetivou avaliar o estado nutricional das plantas, a produção de pêssego, a lixiviação de formas de $\mathrm{N}$ no solo e a volatilização de $\mathrm{N}-\mathrm{NH}_{3}$ em um pomar de pessegueiro com a adição de composto orgânico.

\section{MATERIAL E MÉTODOS}

O experimento foi conduzido em um pomar de pessegueiro da cultivar 'Chimarrita', enxertado sobre porta-enxerto 'Capdeboscq', na densidade de 1.666 plantas por hectare $(1,5 \mathrm{~m}$ entre plantas e $4 \mathrm{~m}$ entre linhas) e conduzido em sistema Ypsilon, no município de Bento Gonçalves (RS) (latitude 299'54.50”S; longitude 51 32'3.87'O). O clima da região é subtropical, tipo $\mathrm{Cfa}$, com precipitação média anual de $1.736 \mathrm{~mm}$, sendo janeiro e fevereiro os meses mais quentes, com médias máximas de $27^{\circ} \mathrm{C}$ e mínimas de $17^{\circ} \mathrm{C}$; e os meses mais frios são junho e julho, com médias mínimas de $8^{\circ} \mathrm{C}$ e máximas de $17^{\circ} \mathrm{C}$. O pomar foi implantado em 2009 em um Cambissolo Húmico e, antes do transplante das mudas, apresentava, na camada de $0-20 \mathrm{~cm}$, as seguintes características: argila $310 \mathrm{~g} \mathrm{~kg}^{-1}$; matéria orgânica $26,5 \mathrm{~g}$ $\mathrm{kg}^{-1} ; \mathrm{pH}$ em água 5,7; Al trocável $0,0 \mathrm{cmol}_{\mathrm{c}} \mathrm{dm}^{-3}, \mathrm{Ca}$ trocável 7,4 $\mathrm{cmol}_{\mathrm{c}} \mathrm{dm}^{-3}$ e $\mathrm{Mg}$ trocável $2,3 \mathrm{cmol}_{\mathrm{c}} \mathrm{dm}^{-3}$ (ambos extraídos por $\mathrm{KCl} 1 \mathrm{~mol} \mathrm{~L}^{-1}$ ); $\mathrm{P}$ disponível $8,6 \mathrm{mg} \mathrm{dm}$ dm $^{-3}$ K trocável 207,9mg dm ${ }^{-3}$ (ambos extraídos por Mehlich 1).

Em julho de 2010, 2011 e 2012, durante o florescimento, os pessegueiros foram submetidos à aplicação de $0,3,6,12$ e 24L de composto por $\mathrm{m}^{2}$ ano $^{-1}$, em delineamento experimental de blocos ao acaso com três parcelas, sendo cada uma formada por cinco plantas, distribuídas ao longo da linha de plantio. As doses aplicadas foram estabelecidas em experimentos prévios em casa de vegetação ao longo de dois anos, nos quais se verificou que as plantas jovens de pessegueiro apresentaram maior altura e produção de matéria seca na dose de $6 \mathrm{~L}$ de composto $\mathrm{m}^{2}$ ano ${ }^{-1} \mathrm{e}$, com isso, estabeleceram-se doses menores e maiores, a partir desta dose de referência. O composto foi aplicado manualmente sobre a superfície do solo, na área da projeção da copa das plantas e sem incorporação. O composto utilizado foi fabricado a partir de resíduos de agroindústrias de suco, como borra e engaço, bem como resíduos de abatedouro de aves e serragem, apresentando a composição química média de 43,2\% de matéria seca, $0,4 \%$ de $\mathrm{N}_{-} \mathrm{NH}_{4}^{+}$, 0,4\% de $\mathrm{N}^{-\mathrm{NO}_{3}}-$; (em totais) 19,3\% de $\mathrm{C}$ orgânico, $2,0 \%$ de $\mathrm{N}, 0,74 \%$ de $\mathrm{P}, 2,4 \%$ de $\mathrm{K}, 8,2 \%$ de $\mathrm{Ca}$, $0,3 \%$ de $\mathrm{Mg}, 18,7 \mathrm{mg} \mathrm{kg}^{-1}$ de $\mathrm{Cu}, 38,4 \mathrm{mg} \mathrm{kg}^{-1}$ de $\mathrm{Zn} \mathrm{e}$ $311 \mathrm{mg} \mathrm{kg}^{-1}$ de $\mathrm{Mn}$; $\mathrm{pH}$ em água 9,0, relação $\mathrm{C} / \mathrm{N}$ 9,65 e densidade de $0,6 \mathrm{~kg} \mathrm{~m}^{-3}$. 
Nas safras de 2010 e 2011, foram coletadas, na 14ㄹ semana, após a plena floração, folhas completas (limbo+pecíolo) da parte média dos ramos do ano nos diferentes lados das plantas (CQFS-RS/SC, 2004). As folhas foram secas em estufa com circulação de ar forçado a $65^{\circ} \mathrm{C}$, moídas e tiveram os teores totais de $\mathrm{N}, \mathrm{P}, \mathrm{K}, \mathrm{Ca}$ e $\mathrm{Mg}$ analisados (TEDESCO et al., 1995). Nas safras de 2010 e 2012 , na plena maturação dos frutos, que coincidiu com o mês de novembro, foram colhidos todos os frutos por planta, que foram contados, pesados e, usando um paquímetro digital, tiveram o diâmetro de dez frutos por planta mensurados.

Em maio de 2012, foram instalados lisímetros de capa porosa de porcelana no solo abaixo da planta central de cada parcela dos tratamentos de 0 e $24 \mathrm{~L}$ de composto $\mathrm{m}^{2}$, nas profundidades de 20 e $40 \mathrm{~cm}$ da linha de plantio dos pessegueiros, abaixo da zona de aplicação do composto orgânico. Os lisímetros foram instalados seguindo procedimento descrito por LORENSINI et al. (2012). Em 27/07, $18 / 09$ e 03/10, correspondente aos 13, 55 e 68 dias após a aplicação do composto, únicos eventos ocorridos e que geraram solução lixiviada, coletou-se a solução do interior dos lisímetros com uma seringa acoplada a uma mangueira, aplicando-se vácuo (25kgf) com uma bomba manual. Em seguida, as amostras de solução do solo foram armazenadas em recipientes plásticos e acondicionadas em isopor com gelo para, posteriormente, serem determinados os teores de $\mathrm{N}^{-\mathrm{NH}_{4}}{ }^{+}$e $\mathrm{N}-\mathrm{NO}_{3}{ }^{-}$(TEDESCO et al., 1995). Com a soma dos valores de $\mathrm{N}_{-} \mathrm{NH}_{4}^{+}$e $\mathrm{N}_{-} \mathrm{NO}_{3}^{-}$, foi obtido o teor de $\mathrm{N}$ mineral.

Em julho de 2012, nos tratamentos 0, 3, 6, 12 e $24 \mathrm{~L}$ de composto por $\mathrm{m}^{2} \mathrm{ano}^{-1}$, foram instaladas as câmaras coletoras de amônia de tipo semiaberto na região onde foi aplicado o composto (NÔMMIK, 1973). As câmaras foram construídas e instaladas seguindo o procedimento descrito detalhadamente por LORENSINI et al. (2012). No período de 17 de julho a 10 de agosto de 2012, correspondente a $23,47,96,120,145,216,241,265,288,335,431$ e 478 horas após a aplicação de composto orgânico, os discos de espuma foram coletados e submetidos a cinco lavagens sucessivas com a solução de $\mathrm{KCl}$ $1 \mathrm{~mol} \mathrm{~L}^{-1}$ para a extração de fosfato de amônio, sendo o volume final ajustado para 1L com a mesma solução de $\mathrm{KCl} 1 \mathrm{~mol} \mathrm{~L}^{-1}$. Posteriormente, uma alíquota de $20 \mathrm{~mL}$ foi retirada e submetida à análise de $\mathrm{N}^{-\mathrm{NH}_{3}}$ (TEDESCO et al., 1995).

Os resultados dos teores totais de nutrientes nas folhas, massa e diâmetro de frutos, e produção foram submetidos à análise de variância e, quando os efeitos foram significativos, ajustaram-se equações de regressão polinomiais. A impossibilidade de se controlar experimentalmente algumas variáveis, como o intervalo das precipitações, implicam a não satisfação de todos os pressupostos da análise de variância para as formas de $\mathrm{N}$ lixiviadas e $\mathrm{N}^{-\mathrm{NH}_{3}}$ volatilizada. Por isso, optou-se por apresentar as médias dos resultados obtidos com seus respectivos desvios padrões, conforme adotado por LORENSINI et al. (2012).

\section{RESULTADOS E DISCUSSÃO}

Estado nutricional e produção de frutos

Nas safras de 2010 e 2011, os teores totais de $\mathrm{N}$ e $\mathrm{K}$ nas folhas completas dos pessegueiros aumentaram de forma quadrática com o aumento da dose de composto aplicado no solo, mas os teores totais de $\mathrm{P}, \mathrm{Ca}$ e $\mathrm{Mg}$ não foram afetados (Tabela 1). $\mathrm{O}$ incremento dos teores de $\mathrm{N}$ e $\mathrm{K}$ nas folhas pode ser atribuído à mineralização do composto e, no caso do $\mathrm{K}$, parte é encontrada na forma livre no resíduo; com posterior incremento dos teores de $\mathrm{N}$ mineral e $\mathrm{K}$ trocável no solo com o aumento da dose aplicada, como observado depois de cada safra (dados não apresentados). Com isso, as raízes dos pessegueiros absorvem formas de $\mathrm{N}$ mineral, especialmente

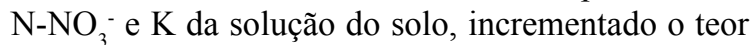
dos dois nutrientes no interior das plantas, o que foi diagnosticado pela análise foliar.

$\mathrm{O}$ incremento de nutrientes no solo, derivados do composto orgânico, e, especialmente, o $\mathrm{N}$ acumulado nas plantas ao longo das safras, diagnosticado pela análise foliar em 2010 e 2011, podem ter contribuído para incrementar a produção de pêssegos na safra de 2010 e até 2012, sem afetar a massa e diâmetro de frutos. No caso da safra de 2012, o $\mathrm{N}$ pode ter contribuído para estimular a diferenciação de um maior número de gemas produtivas nos ramos, comparativamente às gemas vegetativas (MATTOS et al., 1991), incrementando a produção de pêssegos. Convém ressaltar que, nas safras de 2010 e 2012, o diâmetro de frutos, independente das doses de composto, variou entre 5 a $6 \mathrm{~cm}$ e, na safra de 2011 , a massa dos frutos variou entre 80 e próximo a $100 \mathrm{~g}$ (Tabela 1), que são valores considerados adequados e aceitos pelo consumidor (RASEIRA \& NAKASU, 1998). Mas, é oportuno comentar que a produção de pêssego na safra 2012, em todas as doses, foi menor que a obtida na safra de 2010, o que pode ser atribuído ao maior volume de precipitação acumulada entre junho e dezembro, que foi de 1584,6mm, correspondente ao período de aplicação 
Tabela 1 - Teor total de nutrientes nas folhas completas, massa, diâmetro de frutos, e produção, em pessegueiros submetidos à aplicação de composto.

\begin{tabular}{|c|c|c|c|c|c|c|c|}
\hline \multirow{2}{*}{ Variável } & \multicolumn{5}{|c|}{--Dose de composto $\left(\mathrm{L} \mathrm{m}^{-2}\right)$} & \multirow{2}{*}{ Equação } & \multirow{2}{*}{$\mathrm{R}^{2}$} \\
\hline & 0 & 3 & 6 & 12 & 24 & & \\
\hline $\mathrm{N}\left(\mathrm{g} \mathrm{kg}^{-}\right)$ & 14,9 & 16,5 & 15,1 & 16,7 & 15,6 & $\begin{array}{l}y=15,1262+ \\
0,1902 x-0,0070 x^{2}\end{array}$ & $0,58 *$ \\
\hline $\mathrm{P}\left(\mathrm{g} \mathrm{kg}^{-1}\right)$ & 2,4 & 3,2 & 2,7 & 3,3 & 2,8 & ns & - \\
\hline $\mathrm{K}\left(\mathrm{g} \mathrm{kg}^{-1}\right)$ & 13,9 & 16,2 & 15,0 & 16,4 & 15,7 & $\begin{array}{l}y=14,3568+0,278 \\
3 x-0,0093 x^{2}\end{array}$ & $0,73 *$ \\
\hline $\mathrm{Ca}\left(\mathrm{g} \mathrm{kg}^{-1}\right)$ & 9,4 & 8,8 & 9,1 & 8,8 & 9,2 & ns & - \\
\hline $\operatorname{Mg}\left(\mathrm{g} \mathrm{kg}^{-1}\right)$ & 3,2 & 3,1 & 3,1 & 3,2 & 3,1 & ns & - \\
\hline Massa de frutos (g) & 81,3 & 83,3 & 90,7 & 85,8 & 91,7 & ns & - \\
\hline Diâmetro de frutos (mm) & 52,7 & 54,0 & 54,7 & 54,7 & 55,7 & ns & - \\
\hline Produção por hectare $\left(\mathrm{Mg} \mathrm{ha}^{-1}\right)$ & 11,0 & 11,7 & 10,9 & 13,7 & 15,3 & $\begin{array}{l}y=10,8025+0,190 \\
8 x\end{array}$ & $0,94 *$ \\
\hline$N\left(g_{k g}^{-}\right)$ & 22,9 & 25,4 & 24,8 & 26,2 & 28,1 & $\begin{array}{l}y=23,4769+0,30 \\
13 x-0,0046 x^{2}\end{array}$ & $0,94 *$ \\
\hline $\mathrm{P}\left(\mathrm{g} \mathrm{kg}^{-1}\right)$ & 1,7 & 2,1 & 1,7 & 1,6 & 1,5 & ns & - \\
\hline $\mathrm{K}\left(\mathrm{g} \mathrm{kg}^{-1}\right)$ & 19,8 & 21,3 & 24,0 & 28,9 & 18,5 & $\begin{array}{l}y=18,5815+1,47 \\
45 x-0,0611 x^{2}\end{array}$ & $0,95^{*}$ \\
\hline $\mathrm{Ca}\left(\mathrm{g} \mathrm{kg}^{-1}\right)$ & 17,8 & 15,5 & 15,2 & 13,3 & 13,1 & ns & - \\
\hline $\operatorname{Mg}\left(\mathrm{g} \mathrm{kg}^{-1}\right)$ & 4,9 & 4,5 & 4,3 & 4,1 & 4,2 & ns & - \\
\hline Massa de frutos (g) & 66,7 & 69,0 & 75,4 & 77,4 & 75,6 & ns & \\
\hline Diâmetro de frutos (mm) & 45,9 & 46,7 & 48,0 & 49,2 & 47,7 & ns & \\
\hline Produção por hectare $\left(\mathrm{Mg} \mathrm{ha}^{-1}\right)$ & nd & nd & nd & nd & nd & - & - \\
\hline Massa de frutos $(\mathrm{g})$ & 69,9 & 53,6 & 66,7 & 57,2 & 61,5 & ns & - \\
\hline Diâmetro de fruto (mm) & 51,2 & 47,4 & 53,3 & 51,6 & 53,3 & ns & - \\
\hline Produção por hectare $\left(\mathrm{Mg} \mathrm{ha}^{-1}\right)$ & 4,1 & 4,5 & 6,6 & 17,3 & 15,9 & $\begin{array}{l}y=1,9769+1,4739 \\
x-0,0364 x^{2}\end{array}$ & $0,92 *$ \\
\hline
\end{tabular}

ns $=$ não significativo ao nível de $5 \%$ de probabilidade $;{ }^{*}=$ significativa a $5 \%$ de probabilidade; nd $=$ não determinado.

do composto, que foi na brotação, até a colheita dos frutos, comparativamente ao ano de 2010, quando se observaram $401,8 \mathrm{~mm}$. A maior precipitação pode ter estimulado o abortamento de flores, diminuindo a produção de frutos (ALCOBENDAS et al., 2012).

\section{Lixiviação de formas de $\mathrm{N}$}

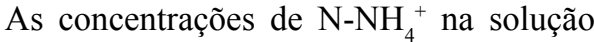
coletada aos 13, 55 e 68 dias após a aplicação (DAA) da dose de composto a $20 \mathrm{~cm}$ de profundidade no solo submetido à aplicação de $24 \mathrm{~L}$ de composto foram iguais às concentrações obtidas no tratamento sem a adição do composto (Figura 1a). Em todas as coletas, as concentrações de $\mathrm{N}_{-} \mathrm{NH}_{4}^{+}$na solução foram próximas de $0,1 \mathrm{mg} \mathrm{L}^{-1}$, indicando que houve pouca lixiviação do $\mathrm{N}$ na forma de $\mathrm{N}-\mathrm{NH}_{4}^{+}$, resultado esperado, uma vez que pode permanecer adsorvido a grupos funcionais de superfície de partículas reativas do solo, mas também pela rápida transformação do $\mathrm{N}-\mathrm{NH}_{4}^{+}$em N-NO ${ }_{2}^{-}$e N-NO ${ }_{3}^{-}$(EARTH et al., 2007).

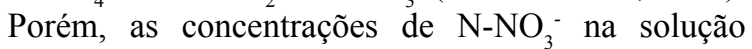
coletada do solo com a adição de $24 \mathrm{~L}$ de composto, e mesmo no solo sem a aplicação, em todas as coletas, continuaram baixas, entre 0 e $0,2 \mathrm{mg} \mathrm{L}^{-1}$ (Figura 1b). Contudo, os teores de $\mathrm{N}^{-\mathrm{NO}_{3}}{ }^{-}$na solução coletada aos 13DAA de composto foi maior no solo submetido à aplicação de 24L, comparativamente ao solo sem aplicação, o que pode decorrer da maior liberação de $\mathrm{N}-\mathrm{NO}_{3}{ }^{-}$dos resíduos orgânicos. Apesar de a liberação de $\mathrm{N}_{-} \mathrm{NO}_{3}{ }^{-}$pelos resíduos ocorrer normalmente próximo aos 20DAA no solo (AITA \& GIACOMINI, 2008), a baixa relação $\mathrm{C} / \mathrm{N}(9,65)$ do composto

Ciência Rural, v.45, n.4, abr, 2015. 


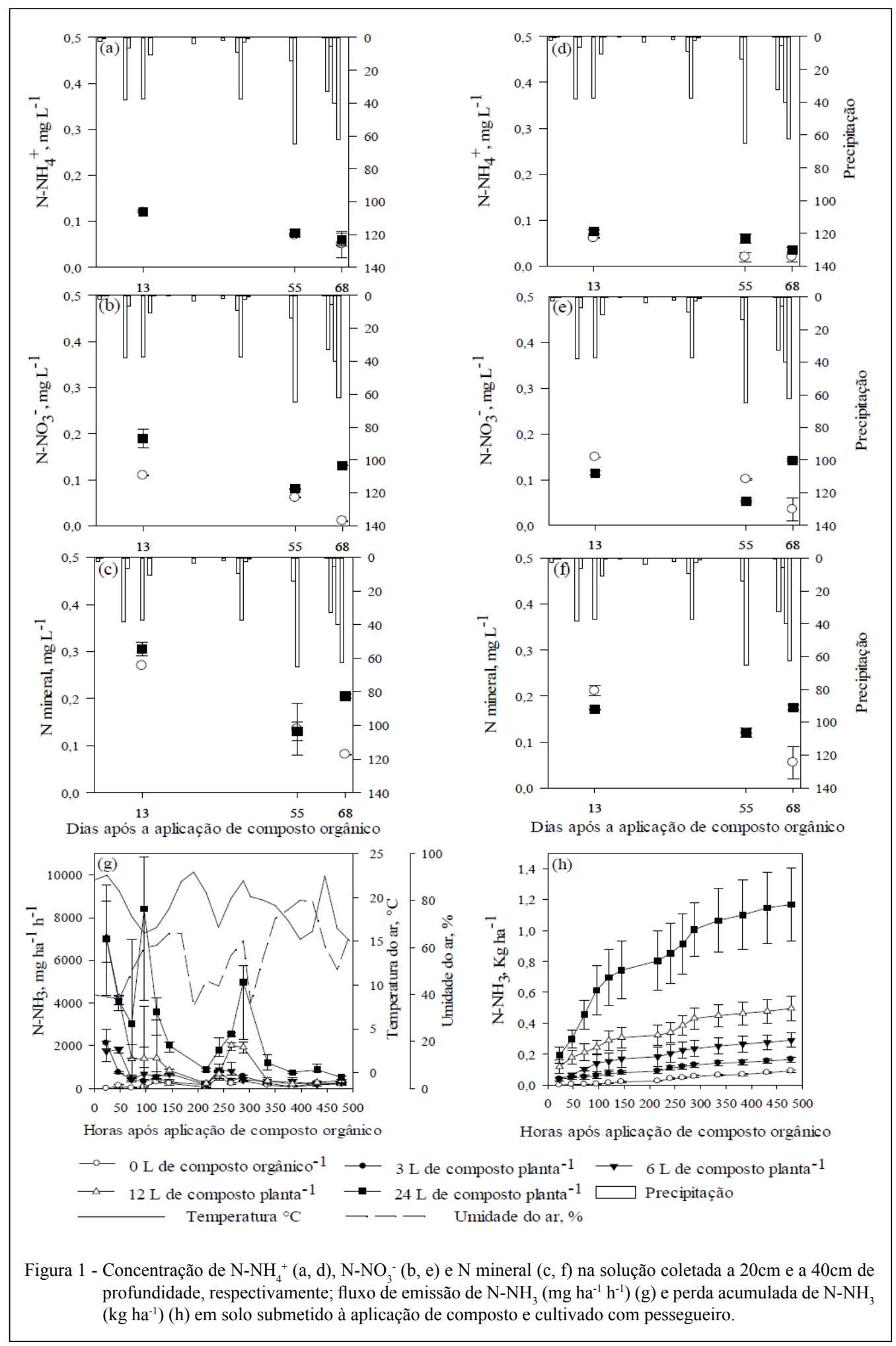

aplicado nos pessegueiros deste experimento pode ter antecipado a liberação de $\mathrm{N}_{-} \mathrm{NO}_{3}^{-}$, incrementando sua concentração na solução. $\mathrm{Na}$ coleta realizada aos 68DAA de composto, a concentração de $\mathrm{N}^{-\mathrm{NO}_{3}}{ }_{3}^{-}$ na solução foi maior no tratamento com adição de $24 \mathrm{~L}$, o que pode ser explicado, em parte, pela maior

Ciência Rural, v.45, n.4, abr, 2015. 
frequência e volume de precipitações nos dias que antecederam a coleta, estimulando a lixiviação de $\mathrm{N}_{-} \mathrm{NO}_{3}^{-}$no perfil do solo, uma vez que o ânion forma complexo de esfera-externa com os grupos funcionais de superfície das partículas reativas do solo (LORENSINI et al., 2012).

A concentração de N-mineral nas coletas realizadas aos 13 e aos 68 DAA do composto foi maior no tratamento com a aplicação de $24 \mathrm{~L}$, comparativamente ao solo sem aplicação (Figura 1c), devido às maiores concentrações de $\mathrm{N}_{-} \mathrm{NO}_{3}^{-}$na solução (Figura 1b). Porém, convém ressaltar que as maiores concentrações de $\mathrm{N}_{-} \mathrm{NO}_{3}^{-}$e $\mathrm{N}$ mineral na solução foram observadas aos 13DAA, o que coincide, aproximadamente, com a brotação dos pessegueiros, que é um dos estágios fenológicos em que acontece a maior emissão de raízes jovens, responsáveis pela absorção de água e maiores quantidades de nutrientes (BRAVO et al., 2012), incrementando o teor de $\mathrm{N}$ no interior da planta (Tabela 1).

As concentrações de $\mathrm{N}-\mathrm{NH}_{4}^{+}$na solução coletada aos 13,55 e $68 \mathrm{DAA}$ a $40 \mathrm{~cm}$ de profundidade foram similares entre o tratamento com a aplicação de 24L de composto e sem aplicação (Figura 1d). Estas concentrações foram semelhantes às observadas nos tratamentos e datas de coletas realizadas na profundidade de $20 \mathrm{~cm}$ (Figura 1a). Por outro lado, as concentrações de $\mathrm{N}_{-} \mathrm{NO}_{3}^{-}$na solução do solo submetido à aplicação de $24 \mathrm{~L}$ de composto orgânico e sem aplicação foram equivalentes nos 13 e 55DAA (Figura 1e), enquanto, aos 68DAA, a concentração de $\mathrm{N}_{-} \mathrm{NO}_{3}^{-}$foi maior na solução derivada do solo com a adição de $24 \mathrm{~L}$ de composto, corroborando os resultados obtidos na profundidade de $20 \mathrm{~cm} \mathrm{e}$ evidenciando a lixiviação de $\mathrm{N}_{-} \mathrm{NO}_{3}^{-}$ao longo do perfil do solo. Já as concentrações de $\mathrm{N}$ mineral na solução coletada a $40 \mathrm{~cm}$ de profundidade aos $13 \mathrm{e}$ 55DAA foram similares no solo com a aplicação de 24L de composto e sem aplicação (Figura 1f). Mas, aos 68DAA, a concentração de $\mathrm{N}$ mineral na solução do solo com a adição de $24 \mathrm{~L}$ de composto foi maior que a obtida no solo sem a aplicação, o que pode ser atribuído ao incremento de $\mathrm{N}_{-} \mathrm{NO}_{3}^{-}$.

Apesar das diferenças entre as concentrações de $\mathrm{N}-\mathrm{NH}_{4}^{+}, \mathrm{N}_{-} \mathrm{NO}_{3}^{-}$e $\mathrm{N}$ mineral na solução do solo do tratamento com a aplicação de 24L de composto e sem aplicação nas diferentes datas de coleta e nas profundidades de 20 e $40 \mathrm{~cm}$ (Figura 1a, 1b, 1c, 1d, 1e e 1f), os valores foram menores que os observados em outros trabalhos, realizados com a aplicação do mesmo composto usado no presente trabalho como fonte de nutriente na adubação de manutenção em pomares de frutíferas
(LORENSINI et al., 2012). Isso pode ser decorrente do valor de $\mathrm{pH}$ do composto $(9,0)$, que estimulou a transferência de parte do $\mathrm{N}$ para a atmosfera na forma de $\mathrm{N}_{-} \mathrm{NH}_{3}$ (VOUTSAS et al., 2005). Além disso, as precipitações foram pouco frequentes e, em geral, de baixa intensidade, o que diminui o fluxo descendente de solução e de formas de $\mathrm{N}$ no perfil do solo (ERHART et al., 2007).

\section{Volatilização de $\mathrm{N}-\mathrm{NH}_{3}$ \\ $\mathrm{O}$ maior fluxo de $\mathrm{N}-\mathrm{NH}_{3}\left(\mathrm{mg} \mathrm{ha}^{-1} \mathrm{~h}^{-1}\right)$ na} maioria das épocas de coleta foi observado no solo submetido à aplicação de $24 \mathrm{~L}$ de composto, sendo as maiores emissões verificadas às 23, 96 e 288 horas (Figura 1g). As maiores emissões de $\mathrm{N}^{-\mathrm{NH}_{3}}$ às $96 \mathrm{e}$ 288 horas aconteceram por que houve um aumento da temperatura nas horas anteriores à coleta nestas duas épocas. A emissão de $\mathrm{N}-\mathrm{NH}_{3}$ às 265 horas correspondeu há aproximadamente 11 dias e, com isso, pode-se inferir que parte do $\mathrm{N}_{-} \mathrm{NH}_{4}^{+}$na solução foi transformado para $\mathrm{N}-\mathrm{NH}_{3}$, uma vez que o teor de $\mathrm{N}_{-} \mathrm{NH}_{4}^{+}$na solução coletada a $20 \mathrm{~cm}$ de profundidade no solo, com a aplicação de $24 \mathrm{~L}$ de composto foi igual ao observado na solução do solo sem adição de composto (Figura 1a). No solo submetido à aplicação de 12L de composto, especialmente, nas coletas realizadas em horas próximas à 96 horas e 288 horas (Figura 1g), a emissão de N-NH foi menor que aquela observada no solo com a adição de $24 \mathrm{~L}$ de composto. Entretanto, o valor foi maior que o verificado no solo dos tratamentos com a aplicação de 0 , 3 e $6 \mathrm{~L}$ de composto, que apresentaram, na maioria das coletas, valores similares de emissão de $\mathrm{N}-\mathrm{NH}_{3}$.

A quantidade volatilizada acumulada de $\mathrm{N}_{-} \mathrm{NH}_{3}\left(\mathrm{~kg} \mathrm{ha}^{-1}\right)$ incrementou com a dose de composto aplicada na superfície do solo (Figura $1 \mathrm{~h}$ ). Assim, ao final de 478 horas, depois da aplicação das doses de composto, observaram-se perdas de aproximadamente 0,$06 ; 0,17 ; 0,27 ; 0,53$ e $1,15 \mathrm{~kg}$ $\mathrm{ha}^{-1}$ de $\mathrm{N}-\mathrm{NH}_{3}$. A volatilização de $\mathrm{N}_{-} \mathrm{NH}_{3}$, derivada do composto aplicado no solo, decorre da rápida mineralização por microrganismos especializados, como bactérias e fungos, formando carbonato de amônio $\left(\mathrm{NH}_{4}^{+}\right)_{2} \mathrm{CO}_{3}$ que não é estável no solo e se decompõe em N-NH, $\mathrm{CO}_{2}$ e água (LORENSINI et al., 2012). Assim, quanto maior a quantidade de $\mathrm{N}$ aplicada na forma de composto, espera-se maior quantidade de $\mathrm{N}_{-} \mathrm{NH}_{3}$ volatilizada. Somado a isso, a volatilização de $\mathrm{N}_{-} \mathrm{NH}_{3}$ também é governada por outros fatores, como precipitação, temperatura e umidade relativa do ar (BOARETTO et al., 2013). A volatilização de $\mathrm{N}_{-} \mathrm{NH}_{3}$ pode diminuir a disponibilidade de formas minerais de $\mathrm{N}$ no solo, o que reduz o aproveitamento pelo pessegueiro. 


\section{CONCLUSÃO}

A aplicação de composto na superfície do solo incrementou o teor de potássio e nitrogênio nas folhas completas, aumentando a produção de frutos. A aplicação de composto no florescimento aumentou a concentração de nitrato na solução do solo, somente na profundidade de $20 \mathrm{~cm}$. A emissão de amônia aumentou com o incremento da dose de composto aplicado, especialmente e nos períodos de maior temperatura.

\section{AGRADECIMENTOS}

À Coordenação de Aperfeiçoamento de Pessoa de Nível Superior (CAPES) e à Empresa Brasileira de Pesquisa Agropecuária (EMBRAPA) (Processo n. 001/2011), pelo apoio financeiro. Ao Conselho Nacional de Desenvolvimento Científico e Tecnológico $(\mathrm{CNPq})$, pela bolsa de Produtividade em Pesquisa concedida ao VI e VII autores.

\section{REFERÊNCIAS}

ALCOBENDAS, R. et al. Combined effects of irrigation, crop load and fruit position on size, color and firmness of fruits in na extra-early cultivar of peach. Scientia Horticulturae. v.142, p.128-135, 2012

AITA, C.; GIACOMINI, S.J. Nitrato no solo com a aplicação de dejetos líquidos de suínos no milho em plantio direto. Revista Brasileira de Ciência do Solo, v.32, p.195-205, 2008. Diponível em: $<\mathrm{http}$ ://dx.doi.org/10.1590/S0100-06832008000500031>. Acesso em: 18 jul. 2013. doi: 10.1590/S0100-06832008000500031.

BOARETTO, R.M. et al. Absorption of ${ }^{15} \mathrm{NH}_{3}$ volatilized from urea by Citrus trees. Plant and Soil, v.365, p.283-290, 2013.

BRAVO, K. et al. Effect of organic fertilization on carbon assimilation and partitioning in bearing nectarine trees. Scientia Horticulturae, v.137, p.100-106, 2012.

BRUNETTO, G. et al. Adubação nitrogenada em ciclos consecutivos e seu impacto na produção e na qualidade do pêssego. Pesquisa Agropecuária Brasileira, v.42, p.17211725 , 2007. Disponível em: <http://dx.doi.org/10.1590/S0100204X2007001200008>. Acesso em: 18 jul. 2013. doi: 10.1590 S0100-204X2007001200008

COMISSÃO DE QUÍMICA E FERTILIDADE DO SOLO - RS/ SC. Manual de adubação e calagem para os Estados do Rio
Grande do Sul e de Santa Catarina. 10 ed. Porto Alegre: SBCS Núcleo Regional Sul/UFRGS, 2004. 400p.

ERHART, E. et al. Nitrogen leaching losses under crops fertilizes with biowaste compost compared with mineral fertilization. Journal Plant Nutrition Soil Science, v.170, p.608-614, 2007.

KRAMER, A.W. et al. Combining fertilizer and organic inputs to synchronize $\mathrm{N}$ supply in alternative cropping systems in California. Agriculture, Ecosystems \& Environment, v.18, p.233-243, 2002.

LORENSINI, F. et al. Lixiviação e volatilização de nitrogênio em um Argissolo cultivado com videira submetida à adubação nitrogenada. Ciência Rural, v.42, p.1173-1179, 2012. Disponível em: <http:// dx.doi.org/10.1590/S0103-84782012005000038>. Acesso em: 18 jul. 2013. doi: 10.1590/S0103-84782012005000038.

MATTOS, M.L.T. et al. Produção do pessegueiro cv. 'Diamante' sob diferentes doses nitrogênio aplicado ao solo. Pesquisa Agropecuária Brasileira, v.24, p.1315-1321, 1991.

MATTOS JUNIOR, D. et al. Nitrogen volatilization and mineralization in a Sandy Entisol Under Citrus. Communications in Soil Science and Plant Analysis, v.34, p.13-14, 2003.

MELO, G.W.B. et al. Resposta das videiras a diferentes modos de distribuição de composto orgânico no solo. Revista Brasileira de Fruticultura, v.34, p.493-503, 2012. Disponível em: <http:// dx.doi.org/10.1590/S0100-29452012000200023>. Acesso em: 18 jul. 2013. doi: 10.1590/S0100-29452012000200023.

NÖMMIK, H. The effect of pellet size on the ammonia loss from urea applied to forest. Plant and Soil, v.39, p.309-318, 1973.

RASEIRA, M.C.B.; NAKASU, B.H. Cultivares: descricão e recomendação. In: MEDEIROS, C.A.B.; RASEIRA, M.C.B. (Ed.). A cultura do pessegueiro. Brasília: Embrapa-SPI; Pelotas: Embrapa-CPACT, 1998. p.29-99.

ROSEN, C.J.; ALLAN, D.L. Exploring the benefits of organic nutrient sources for crop production and soil quality. Hortechnology, v.17, n.4, p.422-430, 2007.

SCANDELARI, F. et al. Seasonal pattern of net nitrogen rhizodeposition from peach (Prunus persica (L.) Batsch) trees in solis with diferente textures. Agriculture, Ecosystems and Environment, v.136, p.162-168, 2010.

TEDESCO, M.J. et al. Análise de solo, plantas e outros materiais. Porto Alegre: Departamento de Solos/UFRGS, 1995. 174p.

VOUTSAS, E. et al. Estimation of the volatilization of organic compounds from soil surfaces. Chemosphere, v.58, p.751-758, 2005 